The final publication is available at Springer via http://dx.doi.org/10.1007/s10739-017-9488-5

\title{
How fast does Darwin's elephant population grow?
}

János Podani ${ }^{1,2}$, Ádám Kun ${ }^{2}$, András Szilágyi ${ }^{3}$

1 Department of Plant Systematics, Ecology and Theoretical Biology, Institute of Biology, Eötvös University, Pázmány P. s. 1.C, H-1117 Budapest, Hungary. Corresponding author. Email: podani@ludens.elte.hu

2 MTA-ELTE-MTM Ecology Research Group, Eötvös University, Pázmány P. s. 1.C, H1117 Budapest, Hungary

3 MTA-ELTE Theoretical Biology and Evolutionary Ecology Research Group, Eötvös University, Pázmány P. s. 1.C, H-1117 Budapest, Hungary

\begin{abstract}
In "The Origin of Species", Darwin describes a hypothetical example illustrating that large, slowly reproducing mammals such as the elephant can reach very large numbers if population growth is not affected by regulating factors. The elephant example has since been cited in various forms in a wide variety of books, ranging from educational material to encyclopedias. However, Darwin's text was changed over the six editions of the book, although some errors in the mathematics persisted throughout. In addition, full details of the problem remained hidden in his correspondence with readers of the Origin. As a result, Darwin's example is very often misinterpreted, misunderstood or presented as if it were a fact. We show that the population growth of Darwin's elephant population can be modeled by the Leslie matrix method, which we generalize here to males as well. Darwin's most often cited figure, about 19 million elephants after 750 years is not a typical outcome, actually a very unlikely result under more realistic, although still hypothetical situations. We provide a recursion formula suggesting that Darwin's original model corresponds to a tribonacci series, a proof showing that sex ratio is constant over all age classes, and a derivation of a generating function of the sequence.
\end{abstract}

Keywords: Darwin's correspondence, Leslie matrix, population growth, The Origin of Species, tribonacci series.

Acknowledgement: We are grateful to I. Scheuring and G. Székely for their comments on mathematical formalism. We are also indebted to the anonymous referees for their constructive criticism and suggestions. 


\section{Introduction}

One of the main pillars supporting Charles Robert Darwin's theory of natural selection (Darwin 1859-1872) is the principle of rapid growth: populations of self-reproducing organisms can increase in size in an exponential function of time unless affected by regulating factors (Pásztor et al. 2016). As is well known, Darwin was indebted to his reading of the sixth edition of Thomas Robert Malthus's Essay on the Principle of Population, which he had read in 1838 , for this insight ${ }^{1}$. In that essay, Malthus had argued that population growth increased exponentially in the context of resources that could, at best, increase only in a linear fashion ${ }^{2}$. Central to Darwin's theory is the statement in "The struggle for existence", the third chapter of Origin: "There is no exception to the rule that every organic being naturally increases at so high a rate, that if not destroyed, the earth would soon be covered by the progeny of a single pair" (Darwin 1859, p. 64). As an illustration of the growing potential of biological populations, Darwin then refers to Linnaeus' work. The great Swedish naturalist was apparently the first who played with this idea when attempting to explain how the Earth was populated starting from - as he believed - the single initial pair of each sexual species (Egerton 2012, p. 82). His hypothetical case was an annual plant with only two seeds produced per year. Darwin clearly felt, however, that a more convincing and vivid example was also needed to make his arguments even stronger. He chose "the slowest breeder of all animals" and the largest terrestrial mammal, the elephant, and explained briefly that the number of descendants from a single pair would be about fifteen million at the end of the fifth century. In the sixth edition of the book, Darwin (1872, p. 51) modified these figures by saying that "after a period of from 740 to 750 years there would be nearly nineteen million elephants alive".

Given the extreme importance of the Origin in the history of biological sciences, the elephant example has received numerous mentions in books, scientific papers and educational material, but little mathematical analysis. In most cases, Darwin's numbers borrowed from either edition were taken as granted, and the elephant example was cited without explaining the circumstances under which the calculations would be arithmetically correct. There are only a

\footnotetext{
${ }^{1}$ In his autobiography written in 1876, Darwin wrote: "Here, then, I had at last got a theory by which to work; but I was so anxious to avoid prejudice, that I determined not for some time to write even the briefest sketch of it" (see Barlow 1958, p. 120, van Wyhe 2002).

${ }^{2}$ Although the majority of historians of science have recognised the significance of Malthus to Darwin's theory of natural selection, they have tended to focus on how his reading of Malthus sat in his relation to his understanding of animal breeding and artificial selection. Indeed, much has been written on both the exact timing of Darwin's reading of Malthus and thus the precise part that this played in the development of his theory of Natural Selection (Hale 2016). However, in making this their focus, they had given too much credence to the key example that Darwin gave to illustrate the power of population growth.
} 
few sources which provide some comments on the matter and, to our knowledge, just one book (Burton 1998, pp. 206-208) that includes a detailed derivation. We feel that we now have the necessary tools to redo the calculations at the highest accuracy and to clarify the misunderstandings that still prevail in the contemporary literature concerning the elephant example. This paper was thus written with three main objectives in mind: 1) to place the elephant example in a historical context and to show the points in which Darwin's presentation of the example was insufficient, 2) to examine the elephant example by elaborated mathematical methods and computer simulation, and 3) to describe situations in which Darwin's numbers are more or less correct. Additionally, for Darwin's original model we derived a recursion formula suggesting that it is in fact a tribonacci series, a proof showing that sex ratio is constant over all age classes, and a derivation of a generating function of the sequence.

\section{A brief history of the elephant example}

The original - and long - manuscript from which the published version of the Origin was extracted (widely known as "Natural Selection”, Stauffer 1975) includes the following passage as the first occurrence of the elephant example in Darwin's works:

"The elephant is supposed not to breed till $<20>$ perhaps 30 years old; its length of life is not known, but as one of unknown age when taken lived according to Dr. Falconer 120 years, I think it will not be an exaggerated statement to take $<80>90$ years as the possible duration of life $\&$ that each pair produces $<$ four $>$ three pair of young: in this case from one pair there will be at the end of 500 years 5,111,514 elephants alive: or if we assume that the pair produced eight young there would be above fifteen millions alive."

(Bracketed numbers are cancelled in the text.) Unfortunately, Darwin gave no clues as to the accurate derivation of these figures. In 1858-59, when he was alerted to the existence of Wallace's manuscript in which Wallace had outlined an explanation of speciation that was very similar to his own, Darwin had rushed to bring his manuscript into publishable form. As Stauffer $(1975$, p. 1) put it, the Origin is therefore "only an abstract of the manuscript Darwin had originally intended to complete and publish as the formal presentation of his views on evolution". The first printed version of the elephant example illustrates Darwin's haste:

"it will be under the mark to assume that it [the elephant] breeds when thirty years old, and goes on breeding till ninety years old, bringing forth three pair of young in this interval; if this be so, at the end of the fifth century there would be alive fifteen million elephants, descended from the first pair" 
(Darwin 1959, p. 64). The text is shortened and, as a consequence, it is likely that Darwin inadvertendly confused and combined his two previous examples: after giving the starting condition of the first (three pairs) he copied the results (fifteen millions) for the second (four pairs) (Barrett 1977, p. II/158) ${ }^{3}$.

In the subsequent four editions of the Origin, this sentence did not change essentially, for example, "it will be under the mark" was replaced by "it will be safest" in the fifth edition (Darwin 1869, p. 75). The error remained unnoticed until 1869, when at least three letters from readers of the book caused him to revisit his calculations. His response dated "Caerdeon, Barmouth, June 7, 1869" (in print: The Athenaeum, p. 82 in No. 2177, 17 July, 1869) shows that there is clearly some ambiguity in the manner in which Darwin formulated the elephant example:

"I have received a letter from Germany on the increase of the elephant, in which a learned Professor arrives at a totally different result from that of Mr. Garbett, both of which differ from that of your Correspondent 'Ponderer."

Unfortunately, we did not find the letter from the German professor in the archives. Edward L. Garbett suggested there would be 2,400,000 elephants after 500 years and 50,000,000 after six hundred (van Wyhe 2002). The third letter deserves reproduction almost in full:

\footnotetext{
"Perhaps some of your readers will be able to enlighten my dull intellect as to the process of reasoning by which this result is obtained. According to Mr. Darwin's theory, each pair brings forth a pair when it is thirty, when it is sixty, and when it is ninety. Hence if there be one pair in the first year, there will be one pair born in the thirtieth year; these two pairs will produce two pairs in the sixtieth year, and these four will produce four pairs in the ninetieth. After that we have only to add the numbers born in the three preceding periods to find out how many are born in each period; because after they have attained the age of ninety years they cease to breed. This method of reasoning gives the number of pairs born in each period of thirty years as 1, 1, 2, 4, 7, 13, 24, 44, 81, 149, 274, 504, 927, 1,705, 3,136, 5,768, 10,609, 19,513; the last number being born in the period commencing with the five hundred and tenth year. Therefore the number of elephants alive at that time would be 42,762 pairs, that is, 85,524 elephants, less the number that would have died by reason of their age. But Mr. Darwin says that there would be fifteen millions. On what does he base his calculation?"
}

(signed by Ponderer, The Athenaeum, p. 772 in No. 2171, June 5, 1869). The rebuttal by Darwin in his letter of June 7 continues:

\footnotetext{
"Hence you may perhaps think it worth while to publish a rule by which my son, Mr. George Darwin, finds that the product for any number of generations may easily be calculated:
}

\footnotetext{
${ }^{3}$ In a letter to E. Ray Lankaster, April 1872, Darwin nevertheless blamed a mathematician for the error by writing: "I got some mathematician to make the calculation, and he blundered and caused me much shame".
} 
The supposition is that each pair of elephants begins to breed when aged 30, breeds at 60, and again, for the last time, at 90, and dies when aged 100, bringing forth a pair at each birth. We start, then, in the year 0 with a pair of elephants, aged 30. They produce a pair in the year 0, a pair in the year 30, a pair in the year 60, and die in the year 70. In the year 60, then, there will be the following pairs alive, viz.: one aged 90 , one aged 60 , two aged 30 , four aged 0 . The last three sets are the only ones which will breed in the year 90. At each breeding a pair produces a pair, so that the number of pairs produced in the year 90 will be the sum of the three numbers $1,2,4$, i.e. 7 . Henceforward, at each period, there will be sets of pairs, aged 30,60, 90 respectively, which breed. These sets will consist of the pairs born at the three preceding periods respectively. Thus the number of pairs born at any period will be the sum of the three preceding numbers in the series, which gives the number of births at each period; and because the first three terms of this series are $1,2,4$, therefore the series is $1,2,4,7,13,24,44, \&$ c. These are the numbers given by 'Ponderer.' At any period, the whole number of pairs of elephants consists of the young elephants together with the three sets of parents; but since the sum of the three sets of parents is equal in number to the number of young ones, therefore the whole number of pairs is twice the number of young ones, and therefore the whole number of elephants at this period (and for ten years onwards) is four times the corresponding number in the series. In order to obtain the general term of the series, it is necessary to solve an easy equation by the Calculus of Finite Differences."

This is the first occurrence of the starting conditions of the elephant example in print (italics above are added). It is now made clear that Darwin's calendar starts when the first breeding pair is 30 years old, and the female elephant gives birth to twins, always one male and one female, at ages of 30, 60 and 90. George Howard Darwin (1845-1912), Charles Darwin's fifth child, was a mathematician, and his calculations (reproduced here as Fig. 1) yielded the final result of 5,111,514 individuals descended from a single pair after 25 generations, each 30 (?) yr long. ${ }^{4}$ This result is identical to what his father suggested more than 10 years ago in his manuscript (see above). At that time George was about 13 years old, clearly too young to help his father with complicated mathematical problems. That it was neither Charles himself nor George who did the calculations in 1859 turned out from Darwin's next letter written two weeks later (dated Caerleon, North Wales, June 19, 1869, in print: The Athenaeum No. 2174, p. 861, June 26, 1869):

"I am much obliged to your Correspondent of June 5 for having pointed out a great error in my 'Origin of Species,' on the possible rate of increase of the elephant. I inquired from the late Dr. Falconer with respect to the age of breeding, \& c., and understated the data obtained from him, with the intention, vain as it has proved, of not exaggerating the result. Finding that the calculation was difficult, I applied to a good arithmetician; but he did not know any formula by which a result could easily be obtained; and he now informs me that I then applied to some Cambridge mathematician. Who this was I cannot remember, and therefore cannot find out how the error arose. From the many familiar instances of rapid geometrical

\footnotetext{
${ }^{4}$ There is another set of calculations by G. H. Darwin's in which four pairs per mother are used to show that with this condition the population reaches fifteen million after 25 generations (van Wyhe 2002).
} 
increase, I confess that, if the answer had been thirty or sixty million elephants, I should not have felt much surprise; but I ought not to have relied so implicitly on my mathematical friend. I have misled your Correspondent by using language which implies that the elephant produces a pair of young at each birth; but the calculation by this assumption is rendered easier and the result but little different. A friend has extended your Correspondent's calculation to a further period of years. Commencing with a pair of elephants, at the age of thirty, and assuming that they would in each generation survive ten years after the last period of breeding — namely, when ninety years old - there would be, after a period of 750 to 760 years (instead of after 500 years, as I stated in 'The Origin of Species'), considerably more than fifteen million elephants alive, namely, 18,803,080. At the next succeeding period of 780 to 790 years there would be alive no less than $34,584,256$ elephants."

Darwin admits here that the condition of producing twins (our italics above) is not reasonable biologically (twins are born extremely rarely in elephant populations) but a tool of simplifying mathematics. Then, he refers to an (unknown) friend who extended Ponderer's calculations to produce the results rounded up to the next million for the time interval changed to $740-750$ in the 6th edition of the Origin:

“...it will be safest to assume that it begins breeding when thirty years old, and goes on breeding till ninety years old, bringing forth six young in the interval, and surviving till one hundred years old; if this be so, after a period of from 740 to 750 years there would be nearly nineteen million elephants alive, descended from the first pair."

(Darwin 1872, p. 51). It is unfortunate that this edition, the last one handled by Darwin and the most often cited and translated, omits the initial conditions (calendar, when are the calves born) and releases the implicit sex ratio of 50:50\% by replacing "three pair of young" with "six young" - the latter implying this ratio to lie anywhere from 1:5 to 5:1.

\section{Current references to the elephant example}

No surprise then that the literature is extremely heterogeneous in the manner in which the elephant example has been cited, presented and commented upon ${ }^{5}$. The 1859 version of this is mentioned even in fairly recent books, for example Delson et al. (2000, p. 255) who talk about "generation time of one offspring every ten years", which Darwin never said. Modern versions (renditions) may simply reprint the sentences from the first edition (Duzdevich 2014, p. 40). Several authors cite the paragraph without comment on the veracity of the mathematics involved (Chapman and Reiss 1999, p. 37, Sapp 2003, p. 29, Francis 2007, p. 142, Lyons 2011, Garvey 2014, p. 9, Hale 2014, p. 50, Walsh 2015, p. 49). Sometimes, only fragments of

\footnotetext{
${ }^{5}$ We do not refer here deliberately to many book reviews and other reflections that were published immediately after various editions of the Origin. We do not cite Lyell, either, who mentioned the elephant example in the Principles of Geology vol. II in 1883. Also, our literature overview is not meant to be complete - we hope that the subject matter is illuminated satisfactorily on the basis of references that were directly available to us.
} 
the elephant example are extracted from the first edition mentioning only "fifteen million descendants after five centuries" (Eldredge 1985, p. 35, Megarry 1995, p. 33, Benz 2000, p. 197, Gore and Pranjpe 2001, p. 11, Richards 2000, p. 13, Quammen 2006, p. 188, Bashford 2014, p. 38, Kingsland 1995, p. 9, Koch 2014, Chapter 1) or fifteen million elephants "suddenly appearing" (Johnson 2012). Starting from biologically realistic assumptions, McKee (2000, p. 155) replaces fifteen million by a more conservative estimate of nine million elephants after five centuries, without giving any detail of calculation.

Understandably, the example from the $6^{\text {th }}$ edition is more common in the present literature and the way the elephant example is described greatly varies. Typically, many authors refer to 19 million elephants after (740-) 750 years without mentioning other initial criteria of calculation (Blainey 1988, p. 38, Bulhof 1992, p. 98, Overy 1997, p. 53, Tattersall 2000, p. 156, Khanna 2004, p. 2, Tobin and Dusheck 2005, p. 321, Beeby and Brennan 2008, p. 72 , Russell et al. 2008, p. 420, Dash and Dash 2009, p. 26, among others). We know at least one secondary-school text (Lénárd 2007, p. 115) which mentions twenty million elephants with no reference to the source. Additional details (e.g., six youngs between 30-90) are less common (Eldredge 1998, p. 58, Raven et al. 2012, p. 86, Crow 2013, p. 611, Dyer 2014, p. 8). Berg et al. (2010, p. 148) illustrate unlimited growth by mentioning 15 million elephants after 750 years, a confounded example that disappeared from the next edition of their book. Entire passages from Darwin (1872) are occasionally reproduced without further comments (Spellman 2007, p. 168). Eldredge (1997, p. 5), Eysenck (2004, p. 30), Pandey (2010, p. 75) and Sutherland (2014) cite the 1859 book while describing the 1872 example. Stebbing (2011, p. 38) gives full details, but according to his Figure 2.5 the number of elephants in year 750 is $10^{10}$. Nadeau (2013, p. 69) cites this example in order to criticize Darwin who attributed the limits of population growth only to external factors (for Nadeau, however, overcrowding is internal rather than external - a debatable issue). Sometimes, numbers in the elephant example are handled as facts (e.g., "The reproductive abilities of organisms are staggering", Moore and Moore 2006, p. 44). Hardin (1993, p. 87) elaborates the example to calculate the number of years necessary to cover the land area of the earth entirely by elephants $(=1484$ years, a figure cited in turn by McPherson 2005, p. 23).

Relatively few authors have recognized the difference between various editions of the Origin. The modifications of the elephant example were first pointed out in Peckham's (1959, p. 148) comparative analysis. Dennett (1995, p. 40) devotes a footnote to the change. Cronin (1991, p. 271) speaks of 15 million elephants after 500 years commenting that there are revised figures 
in the $6^{\text {th }}$ edition of the Origin. Burton (1998, p. 206) also recognizes the changes and provides detailed calculations to be discussed later in this paper. In the critical edition of the book, Costa (2011, p. 64) raised first some substantial reservations on the general validity of the elephant example, by referring to an anonymous blogger: "the algorithm and the starting assumptions... are something of a mystery". The blogger points out that the sex ratio greatly influences the final result, argues that 15 million after 500 years is correct for 5:1 dominance of the females and suggests that the $6^{\text {th }}$ edition used only an even proportion of the two sexes.

\section{The Leslie matrix approach}

Precise calculation of the elephant example is achieved through the Leslie matrix model (Leslie 1945), a popular computational tool in ecology. It has been developed to describe unlimited growth of age-structured populations over time, i.e., without the interference of any limiting factors and migration. The population is divided into age classes, such as years or other periods of any length. The model applies to one sex, usually the females. If the population has $\omega$ age classes, then the number of female individuals within each class $i$ at time $t$, denoted by $n_{i}^{f}(t)$ may be written into the count vector $\mathbf{n}^{f}(t)$ (although time is discrete in this model, we use the bracketed function notation for transparency). Two parameter sets are required to calculate propulation size in time $t+1$ based on the count vector of time $t$. Survival rate, $0 \leq s_{i} \leq 1$, is the fraction of individuals in age class $i$ which survives to the next class $i+1$, and fecundity $f_{i}^{f}$, the average number of per capita female offspring (reaching age class 1 ) born from females of age class $i$. Thus, population size of the first age class at time $t+1$ is $n_{1}^{f}(t+1)=\sum_{i=1}^{\omega-1} f_{i}^{f} n_{i}^{f}(t)$, while for higher age classes $n_{j+1}^{f}(t+1)=s_{j} n_{j}^{f}(t), \quad(j=2,3, \ldots, \omega-1)$.

Combining these equations into matrix form, we get the following dynamics for females

$$
\left(\begin{array}{l}
n_{1}^{f}(t+1) \\
n_{2}^{f}(t+1) \\
n_{3}^{f}(t+1) \\
\vdots \\
n_{\omega}^{f}(t+1)
\end{array}\right)=\left(\begin{array}{llllll}
f_{1}^{f} & f_{2}^{f} & f_{3}^{f} & \cdots & f_{\omega-1}^{f} & 0 \\
s_{1} & 0 & 0 & \cdots & 0 & 0 \\
0 & s_{2} & 0 & \cdots & 0 & 0 \\
\vdots & \vdots & \vdots & \ddots & \vdots & \vdots \\
0 & 0 & 0 & \cdots & s_{\omega-1} & 0
\end{array}\right)\left(\begin{array}{l}
n_{1}^{f}(t) \\
n_{2}^{f}(t) \\
n_{3}^{f}(t) \\
\vdots \\
n_{\omega}^{f}(t)
\end{array}\right)
$$

or, in simpler form

$$
\mathbf{n}^{f}(t+1)=\mathbf{L n}^{f}(t)
$$


(Note that the superscript $f$ does not denote power, it denotes females.) The Leslie matrix $\mathbf{L}$ of size $\omega \cdot \omega$ comprises all demographic parameters: fecundities in the first row: $L_{1 j}=f_{j}^{f},(j=1, \ldots, \omega-1)$, survival probabilities of different age classes in the subdiagonal: $L_{i+1, i}=s_{i},(i=1,2, \ldots, \omega-1)$ while all other values are zero.

Males can be incorporated into the dynamics easily. Survival of a male individual from an age class to the next can be handled similarly as for females. By introducing fecundity $f_{i}^{m}$, the average number of per capita male offspring born from mothers of age class $i$ the dynamics of males can be decomposed in the following way:

$$
\mathbf{n}^{m}(t+1)=\mathbf{M}_{b} \mathbf{n}^{f}(t)+\mathbf{M}_{s} \mathbf{n}^{m}(t),
$$

where $\mathbf{n}^{m}(t)$ is the count vector of males at time $t$ which contains the male population sizes at different age classes. The birth matrix $\mathbf{M}_{b}$ and the survival matrix $\mathbf{M}_{s}$ have the following form

$$
\mathbf{M}_{b}=\left(\begin{array}{llllll}
f_{1}^{m} & f_{2}^{m} & f_{3}^{m} & \mathrm{~L} & f_{\omega-1}^{m} & 0 \\
0 & 0 & 0 & \mathrm{~L} & 0 & 0 \\
0 & 0 & 0 & \mathrm{~L} & 0 & 0 \\
\mathrm{M} & \mathrm{M} & \mathrm{M} & 0 & \mathrm{M} & \mathrm{M} \\
0 & 0 & 0 & \mathrm{~L} & 0 & 0
\end{array}\right), \mathbf{M}_{s}=\left(\begin{array}{cccccc}
0 & 0 & 0 & \mathrm{~L} & 0 & 0 \\
s_{1} & 0 & 0 & \mathrm{~L} & 0 & 0 \\
0 & s_{2} & 0 & \mathrm{~L} & 0 & 0 \\
\mathrm{M} & \mathrm{M} & \mathrm{M} & 0 & \mathrm{M} & \mathrm{M} \\
0 & 0 & 0 & \mathrm{~L} & s_{\omega-1} & 0
\end{array}\right)
$$

For sake of simplicity and in line with Darwin's original assumption, we used sexindependent survival rates, but the model introduced above can be extended readily by different survival rates for males and females. When it is assumed that males and females are born to each fertile age class at a constant sex ratio $g=\frac{f_{i}^{m}}{f_{i}^{f}}$, the same ratio holds for the number of male and female individuals in all age classes: $\frac{n_{i}^{m}(t)}{n_{i}^{f}(t)}=g$, for all $i=1,2, \ldots, \omega$ (for proof, see Supplementary Material).

\section{Results for Darwin's elephant example}

We may assume from all available information summarized above that Darwin's model has the following parameters: $\omega=100, f_{29}^{f}=f_{59}^{f}=f_{89}^{f}=1$, all other $f_{i}$-s are zero, $s_{i}=1$ for $i$ $=1 \ldots \omega-1, n_{1}(0)=1$, all other $n$-s are zero at the outset, and $g=1$. Because of the previous results on the constant sex ratio, males need not be considered explicitly. That is, we can use 
Eq. (1) for computing the number of females, the number of males in any age classes will be the same as the number of females. The Leslie matrix model for females then provides the results in Table 1. Years in brackets are numbered starting at the first year when calves are born - for comparability with the original calendar. It is obvious at first glance that Darwin (or rather, his mathematician friend) correctly calculated the results presented in the letter of June 19, 1869 (see above). However, Darwin committed another - and unexplained - error when preparing the $6^{\text {th }}$ edition: in the book he gave "740 to 750 ", rather than the true " 750 to 760 " years for the interval when population size is (roughly) nineteen million!

In the same letter, he did not mention what happened between years 761 and 779. In this period population size dropped to 17.3 million because 1.5 million $100 \mathrm{yr}$ old individuals died in 760. In general, two types of periods alternate regularly, a 10-year and a 20-year period - a fact rarely mentioned in the literature. The short ones have more individuals than the succeeding long periods due to the 10 year survival of more than $90 \mathrm{yr}$ old mother animals. Ponderer gave numbers for the 20-year ones, and probably he started 30 years earlier because 19,513 in Darwin's calendar was in 460-480. How Ponderer obtained 42,762 and its double 85,524 remains unclear. George Darwin's calculations are fine, as far as the numbers are concerned (Fig. 1) - he also presented the numbers for the 20-yr long classes but his final result, $5,111,514$ is in fact not for the $500^{\text {th }}$ but for the $701^{\text {st }}$ year. Obviously, he either erroneously counted the number of 30 year periods or - which is more likely - the periods were only 20 years long for him and he disregarded the 10-year long sections (Fig. 1). Burton (1998, p. 206) observed that the ratio of female population size of two successive $30 \mathrm{yr}$ generations converges to 1.8393 and obtained the approximate result of 18.8 million for 750 years. Burton argued that Darwin might have derived his result using this ratio, but his correspodence confirms that the precise figures resulted from more tedious, detailed calculations based on summing three previous generations before the actual one, as in Fig. 1.

As said, in Darwin's original setup two types of periods alternate. A 10-years long interval (with $a_{n}$ females in the $n^{\text {th }}$ generation) is followed by a 20-years long one (with $a^{\text {' }}{ }_{n}$ females) because of the 10 year survival of old mother animals after their last calves. Thus, the two intervals for $n \geq 1$ are:

$$
\begin{aligned}
& {[30(n-1), 30(n-1)+9]: a_{n} \text { females }} \\
& {[30(n-1)+10,30(n-1)+29]: a_{n}^{\prime} \text { females }}
\end{aligned}
$$


Obviously: $a_{1}=a_{1}^{\prime}=1, a_{2}=a_{2}^{\prime}=2, a_{3}=a_{3}^{\prime}=4$. Extending the series with $a_{0}=a_{0}^{\prime}=1$, from the $4^{\text {th }}$ generation we obtain the following two identities:

$$
\begin{aligned}
& a_{n}=2 a_{n-1}^{\prime} \\
& a_{n}^{\prime}=a_{n}-a_{n-4}^{\prime}
\end{aligned}
$$

By combining the two equations, we get the following recursion for the number of females in the 20-years long period of the $n^{\text {th }}$ generation:

$$
a_{n}^{\prime}=2 a_{n-1}^{\prime}-a_{n-4}^{\prime},(n \geq 4)
$$

The next few elements of the recursion are: $a_{4}^{\prime}=7, a_{5}^{\prime}=13, a_{6}^{\prime}=24$, while $a_{4}=8, a_{5}=14, a_{6}=$ 26 , etc. Thus, the number of females of the $n^{\text {th }}$ generation in the interval [30(n-1), 30(n-1)+9] is $2 a_{n-1}^{\prime}$ (every second value in column 2 of Table 1 , starting with the first row), in the interval of $[30(n-1)+10,30(n-1)+29]$ is $a^{\prime}{ }_{n}$ (every second value in column 2 of Table 1 , starting with the second row), $n>1$. With a more modern mathematical treatment, the general element of the series of the number of elephants can be calculated. In our case, the result is not very instructive, however. In the second (20 years long) interval of the $n^{\text {th }}$ generation the number of females $\left(a_{n}\right)$ is equal to the $n^{\text {th }}$ coefficient of the Maclaurin series expansion of the following function (the so-called generating function):

$$
G(x)=\frac{1}{1-x-x^{2}-x^{3}} .
$$

For proof, see Supplementary Material. (Note that there is a quite complex and less instructive closed-form formula for the $n^{\text {th }}$ element of the series, see e.g. see Noe et al. undated.) It can be seen that the recursion described by Eq. (3) is identical to $a_{n}^{\prime}=a_{n-1}^{\prime}+a_{n-2}^{\prime}+a_{n-3}^{\prime}$ (,,we have only to add the numbers born in the three preceding periods to find out how many are born in each period") - see Supplementary Material. We introduced the new recursion, since it can be interpreted more easily.

We note that the sequence $1,2,4,7,13,24,44, \ldots$ (every second row of Table 1 , starting with row 2) defined by the recursions introduced above is the so-called 'tribonacci series' (for details, see Noe et al. undated). (In some definitions the first three elements of the tribonacci series are $0,1,1$ followed by $1,2,4,7, \ldots)$. This is the generalization of the well-known Fibonacci series (which is defined by the recursion formula: $a_{n}=a_{n-1}+a_{n-2}$ ). We also note that the ratio of adjacent terms of the series $\left(\frac{a_{n}}{a_{n-1}}\right)$ tends to 1.83929 (the tribonacci constant, see Weisstein, undated) as $n \rightarrow \infty$. This constant is the the real root of the characteristic 
polynomial of the recursion, and also the reciprocal of the real root of the expression $1-x-x^{2}-x^{3}$, the denominator of the generating function (for details and proof, see Supplementary Material), a value whose approximation was also devised by Burton (1998, see above). The number of individuals follows the tribonacci series if female individuals die after their age of 90 (after giving birth to their third twin) and before 120 which actually they never reach in the elephant example.

\section{Some more general results}

A natural question arises at this point: how to calculate population sizes when males are born at times different from the birthyears of females? Darwin was wrestling with this problem - as is obvious from his letter of June 19, 1869 - but eventually he convinced himself that the result would be "little different" if males and females were not born in the same year, i.e., if the possibility of twins were excluded. To examine this proposition we used the extended Leslie model of Eqs (1) and (2). WINDOWS application DElephant has been written to perform the computations (available at http://ramet.elte.hu/ p podani).

We first show that Darwin underestimated the effect of relative timing of male and female birthyears. If females are born at their mother's age of 30, 60 and $90\left(f_{29}^{f}=f_{59}^{f}=f_{89}^{f}=1\right.$, as before), and males are born just with a two-year difference from the nearest sister at ages 32 , 62 and 88 of the mother $\left(f_{31}^{m}=f_{61}^{m}=f_{87}^{m}=1\right)$, then in the $750^{\text {th }}$ year total population size is only $14,857,786$ (with 9,401,540 females and 5,456,246 males) - so we can conclude that even the slightest biologically relevant change in the model has enormous effect on the result, in the example, a $21 \%$ difference.

Next, we examine what happens after 750 years if 3 males and 3 females are born alternately with equal time intervals (12 years), first starting with a female calf, and then starting with a male. In the first case, the relevant parameters are $f_{29}^{f}=f_{53}^{f}=f_{77}^{f}=1, f_{41}^{m}=f_{65}^{m}=f_{89}^{m}=1$ all other $f_{i}^{f}$-s and $f_{i}^{m}$-s are zero. After 750 years, there would be 27,573,039 females, $20,994,926$ males and their total of 48,567,965. In the second case with $f_{41}^{f}=f_{65}^{f}=f_{89}^{f}=1$ and $f_{29}^{m}=f_{53}^{m}=f_{77}^{m}=1$, all other $f_{i}^{f}$-s and $f_{i}^{m}$-s are zero we obtain only 713,609 females and 907,388 males. Thus, a total of only 1,620,997 individuals would constitute the elephant population after the same time. These examples show even more convincingly that parametrization of Darwin's model influences the result much more than previously thought. 
To analyze the sensitivity of the growth rate to the number of newborns and the order of birth of males and females we computed the number or individuals at $750^{\text {th }}$ year for a set of different cases. We assumed that all females have six offspring born at the mother's age of 30 , 42, 54, 66, 78 and 90; and that the number of female newborns can vary between 1 and 5 with different temporal distribution. As seen in Figure 2, the size of the population heavily depends not only on the number of female offspring but also on the temporal distribution of females. For example, in the following two situations when 1) there are two female calves and they are born first (and followed by four males) and 2) there are four female calves but the two males are born first, then population size after 750 years will be roughly the same, see arrows in Fig. 2. Also, if we forget about the case of single females - which implies no population growth then we can see in Figure 2 that the productivity of different combinations of male-female birthyears will range from around 2000 to $8 \cdot 10^{10}$.

As said, in case of one female offspring to each mother the population does not grow, the number of individuals oscillates around a constant value (each red circle in Fig. 2 represents such a constant). The later the female is born, the lower is this constant. In any other case, the population grows exponentially.

Another issue to be examined is to estimate the probability of having around 19 million elephants in the $750^{\text {th }}$ year. We start from the more realistic condition that each female gives birth to one male and one female calf in each 20 -year period of her sexual activity from age 30 to 90 , with the assumption that these calves are born at random dates within these short periods. We run the modified Leslie model 10,000 times. The number of cases when population size was between 17.5 and 20.5 million was only 327. That is, Darwin's so-often cited elephant example easily misleads the reader: to have 19 million or so individuals in year 750 is in fact a very unlikely situation, with an estimated probability of 0.033 , if we assume weak stochasticity in elephant demography and modify Darwin's scenario accordingly.

\section{Discussion}

One of the few numerical examples in the Origin concerns the population growth of elephants in the strictly theoretical sense. It has become widely dispersed in the literature of biology and has been cited in many books written in diverse fields ranging from psychology to ecology. This is partly because the statement that, starting from a single pair, the population size of a large mammal can reach 15-19 million within 500-750 years sounds very demonstrative and appealing at the first glance. However, the elephant example is presented in a wide variety of 
ways but mostly without detailed interpetation, thus easily misleading the mathematically naïve reader. It is historically interesting how this case has become overly complicated due to the author, Darwin himself, and to all those who mentioned it uncritically. The point here is not that Darwin, following advice by Falconer, overestimated some critical demographic parameters of elephants ${ }^{6}$ : the minimum age when a female gives birth to its first calf (30), the maximum age an animal can reach (100), as well as the length of the fertile period of this species (60); the problems are in fact mathematical.

In none of the various editions of Origin are all the necessary starting assumptions presented for the exact calculation of the example; full details are given only in a letter that appeared in the weekly periodical, The Athenaeum, its June 26, 1869 issue. In the first five editions, the numbers (15 million elephants after 500 years) were not those Darwin originally meant, whereas the sex ratio was implicitly understood as 1:1. After receiving comments from different readers, Darwin modified the example in the $6^{\text {th }}$ edition. He gave a rounded number for population size (19 million) after a period of 740-750 years. Unfortunately, by mentioning the progeny consisting of "six young", the sex ratio became undefined even implicitly. Based on all available evidence, we reconstructed the problem which is formulated in full as follows: a single pair starting to breed at age 30 when calendar starts, their progeny is always a mixed twin, born when parents are 30,60 and 90 years old, every individual survives until the age 100. The question is how total population size changes in time if no limits are imposed on its growth. We suggest that, although there have been proposals to calculate population number precisely (George H. Darwin's recursion) or approximately (Burton's method of constant ratio) - the most straightforward computation is offered by the Leslie model. If extended and calculated in parallel for the males, as we also suggest here, exact population size can be obtained for more general situations, e.g., with varying order of birth for males and females, different time intervals between birthyears, etc.

We have shown that relatively slight modifications of the starting conditions can have enormous impact on the final number. We illustrated further that, if the restriction of twins

\footnotetext{
${ }^{6}$ Actually, the two traditionally recognized species of elephant differ quite substantially. Long-term data exist for wild African bush elephants (Loxodonta africana) which allow the estimation of demographic parameters for real populations (Lee et al. 2016). A female elephant starts reproducing by the age of 13.86, and then gives birth every 5 years to a single calf (one twin birth has been recorded [Moss 2001]). Their reproductive period lasts until they reach 49 years of age, but they can still live for some more years. The age by which $95 \%$ of the females had died was 65 years, and they might live up to 74 years. The sex ratio was 1:1 (Moss 2001). Demographic data on Asian elephants (Elephas maximus) come from a population of tamed individuals employed in the timber industry in Myanmar (Lahdenperä et al. 2014). There, females start reproduction at the age of 19.9, and give birth every 6 years to a single calf. On average an Asian elephant female produces 2.6 (111) calves during their life. Their reproductive period lasts until they reach 32.5 years of age. The age by which $95 \%$ of the females had died was 57 years, but some individuals can live to up to 80 years.
} 
born 30 years apart is released and calves are allowed to be born more evenly and randomly, then Darwin's figure of around 19 million is very unlikely. Thus, the general statement that a pair of elephants could have that many descendants after 750 years is not substantiated even in the statistical sense. Darwin has been generally recognized as an accurate, diligent and thorough scientist but, in this case he probably underestimated the importance of presenting precise starting conditions. A conclusion is that one must be careful with citing concrete numbers even if the source is a very highly respected and most influential authority. The potential danger is the highest in secondary and high-school level texts which should communicate established knowledge whenever no comments are added to illuminate a given problem more thoroughly. Nevertheless, Darwin's elephant example is still convincing and intuitive - but it must be presented and discussed with care. The application we developed may help the teacher and the student to demonstrate how different final results may be obtained by modifying Darwin's starting criteria in his model. The results we present here will also be interesting, we believe, for the historians of science, given the extent and depth that they have paid to Darwin's Malthusian metaphor across a number of generations. The present study reveals that Darwin's original proposal is closely related to some noted mathematical issues. Population size in each of the 20-year long intervals is a tribonacci number, and thus the sequence of these values corresponds to the tribonacci series. It is the first biologically relevant - although hypothetical - example of this series. Its occurrence in the living world has been shown to be fragmentary at best (see Al-Suwaiyel et al. 2006). This sequence is an extension of the Fibonacci series whose validity in interpreting plant morphological pattern is widely known (Douady and Couder 1996, Brousseau 1969, Niklas 1997, pp. 269-278). Interestingly, the great Italian mathematician L. Fibonacci (born Leonardo Pisano Bigollo, c. 1175 - c. 1250) described the series in a context similar to Darwin's elephant example. Fibonacci started with a pair of rabbits, supposed that they mate at the age of one month, and after one more month the female gives birth to another pair, one male and one female. If the rabbits survive for a year, and mixed twins are born every month to every female, then population size at the end of each month will be a number in the Fibonacci series. Thus, mathematical demography has its roots deeply in the Middle Ages and Burton (1998, p. 211) rightly raises the question of whether Darwin knew about it. Based on the different editions of the Origin and his correspondence which is now open to the public we can definitely say that he did not. It does appear though, that Darwin and his advisors, 
including his son George H. Darwin, did invent the tribonacci series unintentionally ${ }^{7}$, without making reference to Fibonacci and placing the elephant example into a general mathematical context.

\section{References}

Agronomof, M. 1914. "Sur une suite récurrente.” Mathesis 4: 125-126.

Al-Suwaiyel, M. I., Alani, D. and Al-Swailem, A. 2006. "An investigation of Fibonacci-like sequences in biology and mathematics." International Journal of Nonlinear Sciences and Numerical Simulation 7: 133-136.

Barlow, N. 1958. The Autobiography of Charles Darwin 1809-1882. With the original omissions restored. Edited and with appendix and notes by his grand-daughter Nora Barlow. London: Collins.

Barrett, P. H. 1977. The Collected Papers of Charles Darwin. 2 vols. Chicago and London: University of Chicago Press. With a foreword by Theodosius Dobzhansky.

Bashford, A. 2014. Global Population. History, Geopolitics, and Life on Earth. New York: Columbia University Press.

Beeby, A. and Brennan, A.-M. 2008. First Ecology: Ecological Principles and Environmental Issues. 3rd ed. Oxford: Oxford University Press.

Benz, R. 2000. Ecology and Evolution: Islands of Change. Arlington, VA: NSTA Press.

Berg, L. R., Hager, M. C. and Hassenzahl, D. M. 2010. Visualizing Environmental Science. $3^{\text {rd }}$ ed. Hoboken, NJ: Wiley.

Blainey, G. 1988. The Great Seesaw. A New View of the Western World, 1750-2000. Houndmills, Hampshire: MacMillan.

Brousseau, A. 1969. "Fibonacci statistics in conifers." Fibonacci Quarterly 7: 525-32.

Bulhof, I. N. 1992. "The” language of science: A study of the relationship between literature and science in the perspective of a hermeneutical ontology. With a case study of Darwin's The Origin of Species. Leiden: E.J. Brill.

Burton R. F. 1998. Biology by Numbers: An encouragement to quantitative thinking. Cambridge: Cambridge University Press.

Chapman, J. L. and Reiss, M. J. 1999. Ecology: Principles and Applications. 2nd ed. Cambridge: Cambridge University Press.

Costa, J. T. 2011. The Annotated Origin. A Facsimile of the First edition of On the Origin of Species. Boston: Belknap Press of Harward University

Cronin, H. 1991. The Ant and the Peacock. Altruism and sexual selection from Darwin to today. Cambridge: Cambridge University Press.

Crow, W. B. 2013. A Synopsis of Biology. 2nd ed. Bristol: John Wright and Sons.

\footnotetext{
${ }^{7}$ The first mathematical study of the series was published much later by Agronomof (1914) while the term "tribonacci" was coined by Feinberg (1963) as a humorous analogy to Fibonacci.
} 
Darwin, C. R. 1859-1872. The Origin of Species by Means of Natural Selection, or the Preservation of Favoured Races in the Struggle for Life. 1st - 6th editions. London: John Murray.

Dash, M. C. and Dash, S. D. 2009. Fundamentals of Ecology. 3rd ed. New Delhi: Tata McGraw Hill.

Delson, E., Tattersall, I., Van Couvering, J. and Brooks, A. S.(eds.). 2000. Encyclopedia of Human Evolution and Prehistory. 2nd Ed. New York: Routledge.

Dennett, D. C. 1995. Darwin's Dangerous Idea: Evolution and the Meanings of Life. New York: Simon \& Schuster.

Douady, S. and Couder, Y .1996. "Phyllotaxis as a dynamical self organizing process." Journal of Theoretical Biology 178: 255-74.

Duzdevich, D. 2014. Darwin's On the Origin of Species. A Modern Rendition. Bloomington \& Indianapolis: Indiana University Press.

Dyer, A. 2014. Chasing the Red Queen: The Evolutionary Race between Agricultural Pests and Poisons. Washington: Island Press.

Egerton, F. N. 2012. Roots of Ecology. Antiquity to Haeckel. Berkeley: University of California Press.

Eldredge, N. 1985. Frames: The Evolution of Punctuated Equilibria. Princeton: Princeton University Press.

Eldredge, N. 1997. Dominion. Berkeley: University of California Press.

Eldredge, N. 1998. Life in the Balance. Humanity and the Biodiversity Crisis. Princeton: Princeton University Press.

Eysenck, M. W. 2004. Psychology. An International Perspective. Hove, East Sussex: Psychology Press.

Feinberg, M. 1963. "Fibonacci-Tribonacci.” Fibonacci Quarterly 1: 71-74.

Francis K. A. 2007. Charles Darwin and the Origin of Species. Westport, CT: Greenwood Press.

Garvey, B. 2014. Philosophy of Biology. New York: Routledge.

Gore, A. and Paranjpe, S. A. 2001. A Course in Mathematical and Statistical Ecology. Dordrecht: Kluwer.

Hale, P. J. 2014. Political Descent. Malthus, Mutualism and the Politics of Evolution in Victorian England. Chicago: University of Chicago Press.

Hale, P. J. 2016. "Finding a place for the anti-Malthusian tradition in the Victorian evolution debates.” In Mayhew, R. (ed.), New Perspectives on Malthus. Cambridge: Cambridge University Press, pp. 182-207.

Hardin, G. 1993. Living within Limits: Ecology, Economics, and Population Taboos. Oxford: Oxford University Press.

Johnson, P. 2012. Darwin. Portrait of a Genius. New York: Viking.

Khanna, D. R. 2004. Animal Distribution. New Delhi: Discovery. 
Kingsland, S. E. 1995. Modeling Nature. Episodes in the History of Population Ecology. $2^{\text {nd }}$ ed. Chicago: University of Chicago Press.

Koch, R. 2014. The 80/20 Principle and Other Powerful Laws of Nature. London: Brealey.

Lahdenperä, M., Mar, K. U. and Lummaa, V. 2014. "Reproductive cessation and postreproductive lifespan in Asian elephants and pre-industrial humans." Frontiers in Zoology 11: 54-54.

Lee, P. C., Fishlock, V., Webber, C. E. and Moss, C. J. 2016. "The reproductive advantages of a long life: longevity and senescence in wild female African elephants." Behavioral Ecology and Sociobiology 70: 337-345.

Lénárd, G. 2007. Biológia 12. Budapest: Nemzedékek Tudástára.

Leslie, P. H. 1945. "The use of matrices in certain population mathematics.” Biometrika 33: $183-212$.

Lyons, S. 2011. Evolution. The Basics. London: Routledge.

McKee, J. K. 2000. The Riddled Chain: Chance, Coincidence, and Chaos in Human Evolution. New Brunswick: Rutgers University Press.

McPherson, G. R. 2005. Killing the Natives: Has the American Dream Become a Nightmare? Pittsburgh: Whitmore.

Megarry, T. 1995. Society in Prehistory: The Origins of Human Culture. New York: New York University Press.

Moore, J. and Moore, R. 2006. Evolution 101. Westport CT: Greenwood Press.

Moss, C. J. 2001. "The demography of an African elephant (Loxodonta africana) population in Amboseli, Kenya." Journal of Zoology 255: 145-156.

Nadeau, R. L. 2013. Rebirth of the Sacred. Oxford: Oxford University Press.

Niklas, K. J. 1997. The Evolutionary Biology of Plants. Chicago: University of Chicago Press.

Noe, T., Piezas, T. III and Weisstein, E. W. undated. Tribonacci number. From MathWorldA Wolfram Web Resource. http://mathworld.wolfram.com/ TribonacciNumber.html. Accessed 15 December 2016.

Overy, C. 1997. Charles Darwin: His Life, Journeys and Discoveries. A teacher's guide. London: English Heritage Education Service.

Pandey, G. 2010. Bio-cultural Evolution. New Delhi: Concept Publishing.

Pásztor, L., Botta-Dukát, Z., Magyar, G., Czárán, T., Meszéna, G. 2016. Theory-based Ecology: A Darwinian Approach. Oxford: Oxford University Press.

Peckham, M. (ed.). 1959. The Origin of Species: A Variorum Text by C. Darwin. Philadelphia: University of Pennsylvania Press.

Quammen, D. 2006. The Reluctant Mr. Darwin: An Intimate Portrait of Charles Darwin and the Making of his Theory of Evolution. New York: Norton.

Raven, O. H., Berg, L. R. and Hassenzahl, D. M. 2012. Environment. New York: Wiley.

Richards, J. R. 2000. Human Nature after Darwin. A Philosophical Introduction. London: Routledge. 
Russell, P. J., Hertz, P. E. and McMillan, B. 2011. Biology. The Dynamic Science. Vol. 2. Belmont, CA: Thomson.

Sapp, J. 2003. Genesis. The Evolution of Biology. Oxford: Oxford University Press.

Spellman, F. R. 2007. The Science of Water: Concepts and Applications. 2nd Ed. Boca Raton: CRC Press.

Stauffer, R. C. (ed.). 1975. Charles Darwin's Natural Selection; Being the Second Part of his Big Species Book Written from 1856 to 1858. Cambridge: Cambridge University Press.

Stebbing T. 2011. A Cybernetic View of Biological Growth: The Maia Hypothesis. Cambridge: Cambridge University Press.

Sutherland, J. 2014. Jumbo: The Unauthorised Biography of a Victorian Sensation. London: Aurum Press.

Tattersall, I. 2000. “Time and evolution." In Time in Contemporary Intellectual Thought, ed. P. J. N. Baert, Amsterdam: Elsevier. pp. 151-170.

Tobin, A. J. and Dusheck, J. 2005. Asking about Life. Belmont, CA: Thomson.

van Wyhe, J. (ed.). 2002. The Complete Work of Charles Darwin Online. (http://darwinonline.org.uk/). Accessed 15 December 2016.

Walsh, D. M. 2015. Organisms, Agency, and Evolution. Cambridge: Cambridge University Press.

Weisstein, E. W. undated. Tribonacci Constant. From MathWorld-A Wolfram Web Resource. http://mathworld.wolfram.com/TribonacciConstant.html. Accessed 15 December 2016. 


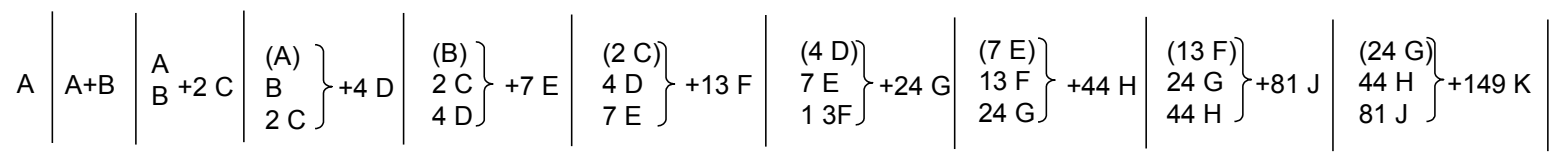

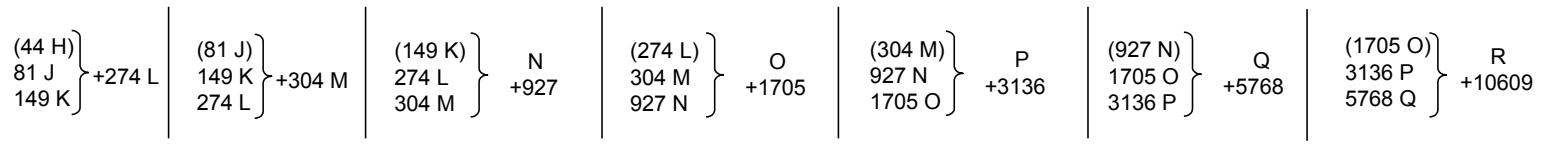

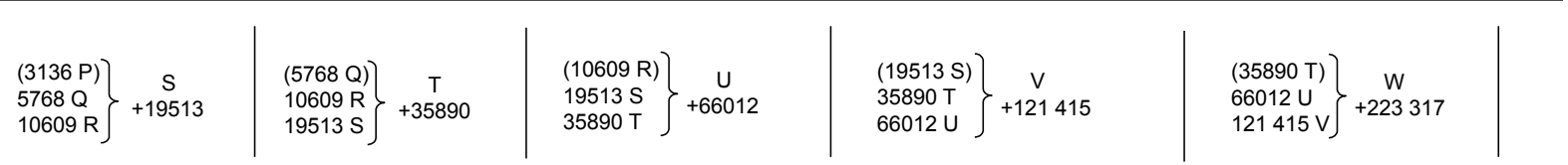

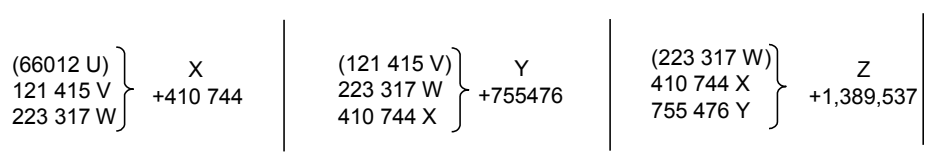

$$
\begin{aligned}
& \begin{array}{l}
410744 X \\
755476 Y
\end{array} \\
& 1,389,537 \mathrm{Z} \\
& 2,555,757 \text { couples } \\
& 5,111,514 \text { individuals alive at end of } \\
& \text { Each letter represents a couple } \\
& 500 \text { years }
\end{aligned}
$$

Fig. 1 George H. Darwin's calculation of the elephant example. Redrawn after an image held in the Cambridge University Library (van Wyhe 2002). Vertical lines are likely to separate 20 year periods. 


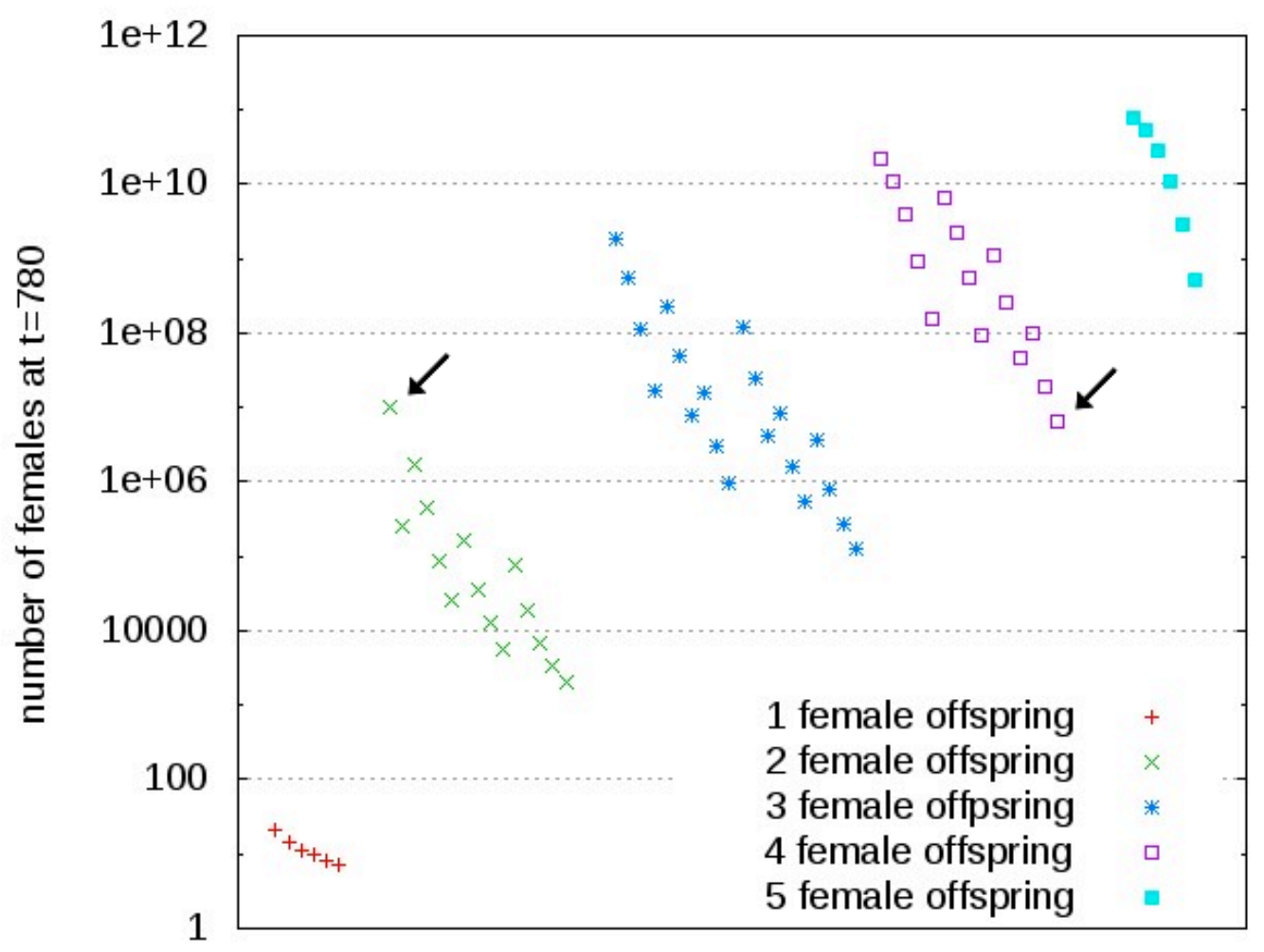

Fig. 2 Total number of individuals after 750 years, with different number and temporal distribution of female offspring. All female individuals have six calves born at the mother's age of 30, 42, 54, 66, 78 and 90. Symbols refer to the number of female offspring, each point corresponds to a particular distribution of females. The leftmost points of each set represent the case when females are born first, while the rightmost points are the opposite cases (e.g. the leftmost green cross is FFMMMM, the rightmost is MMMMFF). Dynamics was started with one male and one female individual at $t=0$. Note that in case of one female calf $(+)$ the number of individual oscillates around a fixed value (growth rate is 1), in all other cases the population grows exponentially. (For the meaning of arrows, see main text.) 
Table 1 Results of the Leslie matrix model for Darwin's elephant example, based on parameters given in the text. Years in brackets are calculated from the birth of the first calf to the 30 year old initial pair corresponding to Darwin's original calendar. Underlined numbers are from Darwin's letter of June 19, 1869. Bold numbers were given by Ponderer. Numbers in italics appear in G. H. Darwin's calculations. * indicates total population size which G. H. Darwin assigned to "the end of 500 years".

\begin{tabular}{|c|c|c|}
\hline Years & No. of females & Population size \\
\hline $0-9$ & 1 & 2 \\
\hline $10-29$ & 1 & 2 \\
\hline $30-39(0-9)$ & 2 & 4 \\
\hline $40-59(10-29)$ & 2 & 4 \\
\hline $60-69$ (30-39) & 4 & 8 \\
\hline $70-89(40-59)$ & 4 & 8 \\
\hline $90-99(60-69)$ & 8 & 16 \\
\hline $100-119$ (70-89) & 7 & 14 \\
\hline $120-129(90-99)$ & 14 & 28 \\
\hline $130-149(100-119)$ & 13 & 26 \\
\hline $150-159(120-129)$ & 26 & 52 \\
\hline $160-179(130-149)$ & 24 & 48 \\
\hline $180-189(150-159)$ & 48 & 96 \\
\hline $190-209(160-179)$ & 44 & 88 \\
\hline $210-219$ (180-189) & 88 & 176 \\
\hline $220-239(190-209)$ & 81 & 162 \\
\hline $240-249$ (210-219) & 162 & 324 \\
\hline $250-269$ (220-239) & 149 & 298 \\
\hline $270-279(240-249)$ & 298 & 596 \\
\hline $280-299$ (250-269) & 274 & 548 \\
\hline $300-309$ (270-279) & 548 & 1096 \\
\hline $310-329$ (280-299) & 504 & 1008 \\
\hline $330-339$ (300-309) & 1008 & 2016 \\
\hline $340-359$ (310-329) & 927 & 1854 \\
\hline $360-369$ (330-339) & 1854 & 3708 \\
\hline $370-389$ (340-359) & 1705 & 3410 \\
\hline 390-399 (360-369) & 3410 & 6820 \\
\hline $400-419$ (370-389) & 3136 & 6272 \\
\hline $420-429$ (390-399) & 6272 & 12544 \\
\hline $430-449$ (400-419) & 5768 & 11536 \\
\hline $450-459$ (420-429) & 11536 & 23072 \\
\hline $460-479$ (430-449) & 10609 & 21218 \\
\hline $480-489$ (450-459) & 21218 & 42436 \\
\hline $490-509$ (460-479) & 19513 & 39026 \\
\hline $510-519$ (480-489) & 39026 & 78052 \\
\hline $520-539$ (490-509) & 35890 & 71780 \\
\hline $540-549$ (510-519) & 71780 & 143560 \\
\hline $550-569$ (520-539) & 66012 & 132024 \\
\hline $570-579$ (540-549) & 132024 & 264048 \\
\hline $580-599$ (550-569) & 121415 & 242830 \\
\hline $600-609$ (570-579) & 242830 & 485660 \\
\hline $610-629$ (580-599) & 223317 & 446634 \\
\hline $630-639(600-609)$ & 446634 & 893268 \\
\hline $640-659$ (610-629) & 410744 & 821488 \\
\hline $660-669$ (630-639) & 821488 & 1642976 \\
\hline $670-689$ (640-659) & 755476 & 1510952 \\
\hline $690-699$ (660-669) & 1510952 & 3021904 \\
\hline 700-719 (670-689) & 1389537 & 2779074 \\
\hline $720-729$ (690-699) & 2779074 & 5558148 \\
\hline 730-749 (700-719) & 2555757 & $5111514^{*}$ \\
\hline
\end{tabular}




\begin{tabular}{|c|c|c|}
\hline $750-759$ (720-729) & 5111514 & 10223028 \\
\hline $760-779$ (730-749) & 4700770 & 9401540 \\
\hline$\underline{780-789}(750-759)$ & 9401540 & 18803080 \\
\hline $\begin{array}{l}790-809 \\
810-819\end{array}$ & $\begin{array}{r}8646064 \\
17292128 \\
\end{array}$ & $\begin{array}{l}17292128 \\
34584256\end{array}$ \\
\hline
\end{tabular}




\section{Supplementary Material}

I. Sex ratio is constant in all age classes

As a first step, it is instructive to introduce the component-wise form of the dynamics for females

$$
\begin{aligned}
& n_{1}^{f}(t+1)=\sum_{i=1}^{k-1} f_{i}^{f} n_{i}^{f}(t) \\
& n_{j+1}^{f}(t+1)=s_{j} n_{j}^{f}(t)
\end{aligned}
$$

and males

$$
\begin{aligned}
& n_{1}^{m}(t+1)=\sum_{i=1}^{k-1} f_{i}^{m} n_{i}^{f}(t) \\
& n_{j+1}^{m}(t+1)=s_{j} n_{j}^{m}(t) .
\end{aligned}
$$

Let the sex ratio of newborns coming from any age class $i$ be constant $g=\frac{f_{i}^{m}}{f_{i}^{f}}$. From Eq. (3), using Eq. (1) and the ratio $g$ we get

$$
n_{1}^{m}(t+1)=\sum_{i=1}^{k-1} f_{i}^{m} n_{i}^{f}(t)=\sum_{i=1}^{k-1} g f_{i}^{f} n_{i}^{f}(t)=g n_{i}^{f}(t+1),
$$

thus, the sex ratio in the first age class follows the ratio of newborns:

$$
g=\frac{n_{1}^{m}(t)}{n_{1}^{f}(t)} .
$$

From Eq. (4) with $j=2$ by using Eq. (2) and the previous result we get the following

$$
n_{2}^{m}(t+1)=s_{1} n_{1}^{m}(t)=s_{1} g n_{1}^{f}(t)=g n_{2}^{f}(t+1) .
$$

Consequently, the same ratio holds for the second age class:

$$
g=\frac{n_{2}^{m}(t)}{n_{2}^{f}(t)} .
$$

As it can be seen easily by induction, the $j$ th age class follows the same ratio:

$$
\begin{gathered}
n_{j+1}^{m}(t+1)=s_{j} n_{j}^{m}(t)=s_{j} g n_{j}^{f}(t)=n_{j+1}^{f}(t+1), \\
g=\frac{n_{j}^{m}(t)}{n_{j}^{f}(t)} .
\end{gathered}
$$


In this section, we derive the characteristic polynomial and a generating function for the recursion introduced in Eq. (3). (For notational simplicity, in this section we omit primes.)

Let the ratio of two subsequent elements of the series in the limit $n \rightarrow \infty$ be $\phi$ :

$$
\phi=\lim _{n \rightarrow \infty} \frac{a_{n}}{a_{n-1}} .
$$

For sufficiently large $n: a_{n-1}=\frac{a_{n}}{\phi}$ and $a_{n-4}=\frac{a_{n}}{\phi^{4}}$, consequently the recursion of Eq. (3) can be written in the following form: $a_{n}=2 \frac{a_{n}}{\phi}-\frac{a_{n}}{\phi^{4}}$. After some rearrangements, we get the characteristic polynomial of the recursion:

$$
\phi^{4}-2 \phi^{3}+1=0
$$

The larger real root of this equation $\phi=\frac{1}{3}+\frac{1}{3}(19+3 \sqrt{33})^{\frac{1}{3}}+\frac{1}{3}(19-3 \sqrt{33})^{\frac{1}{3}} \approx 1.83929 \ldots$ is the tribonacci constant. Note that the characteristic polynomial can be factorized as $\phi^{4}-2 \phi^{3}+1=(\phi-1)\left(\phi^{3}-\phi^{2}-\phi+1\right)$.

Let us introduce

$$
G(x)=\sum_{n=0}^{\infty} a_{n} x^{n}
$$

as the generating function, in which $a_{\mathrm{n}}$-s are the elements of recursion. Multiplying Eq. (3) by $x^{\mathrm{n}}$ and summing from 4 to infinity we get:

$$
\sum_{n=4}^{\infty} a_{n} x^{n}=2 \sum_{n=4}^{\infty} a_{n-1} x^{n}-\sum_{n=4}^{\infty} a_{n-4} x^{n}
$$

The right hand side can be rearranged in the following way:

$$
2 \sum_{n=4}^{\infty} a_{n-1} x^{n}-\sum_{n=4}^{\infty} a_{n-4} x^{n}=2 x \sum_{n=4}^{\infty} a_{n-1} x^{n-1}-x^{4} \sum_{n=4}^{\infty} a_{n-4} x^{n-4}=2 x \sum_{n=3}^{\infty} a_{n} x^{n}-x^{4} \sum_{n=0}^{\infty} a_{n} x^{n}
$$

Taking into account that $\sum_{n=4}^{\infty} a_{n} x^{n}=G(x)-a_{0}-a_{1} x-a_{2} x^{2}-a_{3} x^{3}$ and plugging the result of Eq. (S7) into Eq. (S6) we obtain

$$
G(x)-a_{0}-a_{1} x-a_{2} x^{2}-a_{3} x^{3}=2 x\left(G(x)-a_{0}-a_{1} x-a_{2} x^{2}\right)-G(x) x^{4}
$$

By using $a_{0}=a_{1}=1, a_{2}=2, a_{3}=4$, after some rearrangement we get 


$$
G(x)=\frac{1-x}{x^{4}-2 x+1}=\frac{1}{1-x-x^{2}-x^{3}}
$$

Consequently, from Eq. (S5) it is clear that the coefficients of the Maclaurin series of $G(x)$ are the values of series $a_{n}: \frac{1}{1-x-x^{2}-x^{3}} \approx 1+x+2 x^{2}+4 x^{3}+7 x^{4}+\mathrm{K}$

A straightforward calculation shows that the generating function of the other recursion $\left(a_{n}=a_{n-1}+a_{n-2}+a_{n-3}\right)$ is the same, so that the two recursions are identical.

Note that the characteristic polynomial is the same as the denominator of the generation function written backward (that is, the coefficients are written in reverse order), cf. $\phi^{4}-2 \phi^{3}+1$ and $x^{4}-2 x+1$, for proof see e.g. http://people.math.gatech.edu/ ecroot/recurrence_notes2.pdf. The roots of these two types of plolynomials are the reciprocals of each other, thus the reciprocal of one root of the denominator is the root of the characteristic equation, i.e. the tribonacci constant, as stated in the main text. 